\title{
Antithrombotic prophylaxis of atrial fibrillation in an Italian real-world setting: a retrospective study
}

\author{
Giuliano Ermini' \\ Valentina Perrone ${ }^{2}$ \\ Chiara Veronesi ${ }^{2}$ \\ Luca Degli Esposti² \\ Giuseppe Di Pasquale ${ }^{3}$ \\ On behalf of the GP Group \\ 'General Practice, Bologna, Italy; \\ ${ }^{2} \mathrm{Cli}$ Con S.r.l. Health, Economics and \\ Outcomes Research, Ravenna, Italy; \\ ${ }^{3}$ Department of Cardiology, Maggiore \\ Hospital, Bologna, Italy
}

This article was published in the following Dove Press journal:

Vascular Health and Risk Management

5 July 2017

Number of times this article has been viewed

Correspondence: Luca Degli Esposti CliCon S.r.l, Health, Economics and Outcomes Research, Via Salara, 36, 48100 Ravenna, Italy

Tel +3954438393

Fax +3954421 2699

Email luca.degliesposti@clicon.it
Objectives: The aims of this study were to assess the prevalence of diagnosed atrial fibrillation (AF), the drug use in patients with AF in terms of antithrombotic (AT) strategies used and the compliance with treatment, and to describe the characteristics of patients affected by AF in relation to treatment.

Methods: The data collected were provided from databases of general practitioners (GPs) of the Local Health Unit of Bologna in Italy. From January 1, 2009, to December 31, 2012, all subjects aged $\geq 18$ years followed by the 44 GPs enrolled in the study were evaluated, and the subjects with a diagnosis of AF were included in the analysis.

Results: From 2009 to 2012, we identified 1,413 patients with a diagnosis of AF $(2.09 \%$ of $67,517$ patients of the $44 \mathrm{GPs})$. A total of 1,413 patients with a diagnosis of AF $(2.09 \%$ of 67,517 patients of the 44 GPs) were enrolled in the study. During the study, $14 \%$ of the enrolled patients did not receive any prescription of ATs, 30\% and 39.56\% were treated only with antiplatelet (AP) agents and oral anticoagulants (OACs), respectively, and $16.28 \%$ of the patients received prescriptions for both an $\mathrm{OAC}$ and an $\mathrm{AP}$ agent; of the patients receiving prescriptions for both, only $4.17 \%$ received these therapies at the same time. Among the OAC users, the percentage of patients still on treatment with the index drug during the last 3 months of observation was $76.9 \%$. Conclusion: Our findings emphasize that in an Italian real-world setting, the burden of AF in general population from a public health point of view underscores the need for improvement in utilization of appropriate ATs in patients with known AF.

Keywords: atrial fibrillation, oral anticoagulant, antiplatelet agents, general practitioner, real world

\section{Introduction}

Atrial fibrillation (AF) is the most common type of cardiac arrhythmia, occurring in $1-2 \%$ of the general population worldwide; the prevalence of AF increases steeply with age, from $<0.5 \%$ at $40-50$ years to $5-15 \%$ at 80 years. ${ }^{1,2}$ Men are more often affected than women. ${ }^{3,4}$ In all, $>6$ million Europeans suffer from this arrhythmia, and its prevalence is estimated to double in the next 50 years as the population ages. ${ }^{1}$

AF is often associated with increased rates of death, stroke and other thromboembolic events; hospitalization; and degraded quality of life. ${ }^{5}$ Because the success of therapy depends on the individual patient's underlying level of risk, an accurate stratification of patients' level of risk is needed to select the appropriate therapeutic strategy. ${ }^{6}$ Current national and international practice guidelines for the optimal management of patients with AF recommend careful consideration of individual factors and baseline comorbidities when choosing the most appropriate antithrombotic (AT) 
agent. ${ }^{7-9}$ Consistently, numerous risk stratification schemes have been developed to predict the level of risk profile in patients and to manage patients accordingly. ${ }^{10}$

Oral anticoagulants (OACs), also called vitamin $\mathrm{K}$ antagonists (VKAs), are an effective primary preventive intervention for patients with $\mathrm{AF}$ at a moderate and high risk of stroke. ${ }^{1,11}$ Nevertheless, these agents are associated with a number of limitations, including, when not adequately controlled, a risk of bleeding.

Antiplatelet (AP) agents have been widely used for stroke prophylaxis in patients with AF, particularly in patients with nonvalvular $\mathrm{AF}$ who are considered at a low risk of stroke or in patients in whom OAC therapy is contraindicated. ${ }^{5}$

A number of studies have demonstrated that maintaining the intensity of anticoagulation is crucial to achieving effective stroke prevention and for avoiding bleeding complications. ${ }^{12,13}$ Some studies have examined OACs utilization in a "real-life" setting through administrative claims databases and have reported that their use is suboptimal. ${ }^{14-16}$

In view of these findings, AF management represents a considerable cost burden on health care systems, and strategies to improve the entire process of AF care should be suggested based on knowledge obtained from real-world scenarios.

The aims of this retrospective cohort study were to assess the prevalence of AF diagnoses, the drug usage in patients with $\mathrm{AF}$ in terms of the AT strategies used and the compliance with treatment and to describe the characteristics of patients affected by AF in relation to treatment.

\section{Methods}

\section{Data sources}

This study collected data from databases of 44 general practitioners (GPs) of the Local Health Unit (LHU) of Bologna in Italy. The structure of this database has been described in detail elsewhere. ${ }^{17,18}$

Briefly, the database included different sections as follows: 1) patient data, such as gender and date of birth; 2) prescription records with information on the drugs dispensed by the retail pharmacies in the territory; 3 ) hospital data, the discharge diagnosis codes classified according to the International Classification of Diseases, Ninth Revision, Clinical Modification (ICD-9-CM); 4) prescription records for diagnostic tests and 5) the exemptions database, records for exemptions, which includes the exemption code (identifying the disease for which the exemption was granted). All drugs prescribed were classified according to the codes of International Anatomic Therapeutic Chemical
(ATC) Classification System. In compliance with privacy laws, the patients' identification codes were encrypted. The sections were linked by an encrypted unique identification code according to the Italian law for confidentiality data. No identifiers linking individuals to the data were provided to the researchers, and the authors were never involved in collecting the patient data from patients at any point. The anonymous data file was routinely used by the regional health authorities for epidemiological and administrative purposes. Informed consent was not required for using encrypted retrospective information. This study was notified to the local ethics committee of each participating LHU according to the Italian law regarding the conduct of observational analysis, and the ethics committee of LHU approved the study. ${ }^{19}$

\section{Study population}

From January 1, 2009, to December 31, 2012, the patient files of all subjects aged $\geq 18$ years cared by the 44 GPs enrolled in the study were analyzed, and the subjects with a diagnosis of AF (supported by electrocardiographic findings or the diagnosis recorded on a hospital discharge summary) were included in the analysis.

The index date was defined as the date of the first qualifying AF diagnosis, and all patients enrolled were followed for 1 year after the enrollment date. According to their first prescription of ATs during the enrollment period, the patients were stratified into the following four main categories: 1) monotherapy with OACs (warfarin or acenocumarol); 2) monotherapy with APs (acetylsalicylic acid or clopidogrel); 3) prescriptions of both an OAC agent and an AP agent and 4) without therapy.

The $\mathrm{CHA}_{2} \mathrm{DS}_{2}$-VASc score ${ }^{1}$ (where points are attributed to the presence of known risk factors: congestive heart failure or left ventricular systolic dysfunction, hypertension history, vascular disease, age $\geq 75$ years, diabetes mellitus, prior stroke/transient ischemic attack [TIA] or thromboembolism and gender category) was calculated, and the patients were stratified in various risk levels; a score of $\geq 2$ indicated a risk for thromboembolism requiring anticoagulation. The scores considered in this study ranged from 0 to $5+$. Because the risk of bleeding is also an important concern, ${ }^{9}$ the HAS-BLED (hypertension, abnormal renal and liver function, stroke, bleeding, labile international normalized ratio [INR], elderly [age $>65$ years], drugs [other AP agents or nonsteroidal antiinflammatory drugs \{NSAIDs $\}$ ] or alcohol history) score was calculated to evaluate an individual patient's risk for bleeding. ${ }^{1}$ An HAS-BLED score of $\geq 3$ is associated with a high bleeding risk. The HAS-BLED score was categorized as 0 
through $5+$ in this study. Because in our database information on labile INR and alcohol use was not available for all patients according to a previous analysis, ${ }^{20}$ we calculated a modified HAS-BLED score with a maximum score of 8 instead of 9 . The $\mathrm{CHA}_{2} \mathrm{DS}_{2}$-VASc and HAS-BLED scores were calculated only for patients for whom gender data were available.

When available, the number of INR tests in the period after the index date was assessed. The following covariates were assessed for each patient at the index date: 1) demographic variables; 2) risk factors for stroke, such as previous stroke/TIA/hemorrhagic stroke (ICD-9-CM codes: 430-436, 438, 442), valve disease (ICD-9-CM codes: 394, 424.0), diabetes (ICD-9-CM code: 250), peripheral vascular disease (ICD-9-CM codes: 433.1, 440.2, 443.9), hypertension (ICD-9-CM codes: 401-404), heart failure (ICD-9-CM code: 428 ) and coagulation defects (ICD-9-CM codes: 286, 287); 3) other disease, such as peptic ulcer (ICD-9-CM codes: 531-534); hemorrhage/bleeding (ICD-9-CM codes: 456.0, 531.0, 531.2, 531.4, 531.6, 532.0, 532.2, 532.4, $532.6,533.0,533.2,533.4,533.6,534.0,534.2,534.6$, $569.3,578.0,578.9,596.7,599.7,626.5,626.6,626.9$, 627.0, 627.1, 623.8, 626.2, 784.7, 786.3, 459.0, 719.1, 423.0, 379.2, 852.2); chronic bronchitis (ICD-9-CM code: 491), in particular obstructive chronic bronchitis (ICD-9-CM code: 491.2); asthma (ICD-9-CM code: 493); gastroesophageal reflux (ICD-9-CM code: 530.81); disorders of thyroid gland (ICD-9-CM codes: 240-246); dementia (ICD-9-CM code: 290); other cerebral degenerations (ICD-9-CM code: 331); sleep apnea (ICD-9-CM codes: 780.51, 780.53, 780.57) and bone fractures (ICD-9-CM codes: 805, 806, 808, 820, 824, $812.0-812.5,813.4,813.5,807.0,807.1)$; 4) test prescription and resource usage related to AF management, such as cardiologic visits, echocardiograms (ECGs) and ECG with Holter and mechanical heart valves prior to the index date and 5) all prescriptions due to the use of beta blocker ( $\beta$-blocker) agents (ATC code: C07), statins (ATC code: C10AA), organic nitrates (ATC code: C01DA), antidiabetic drugs (ATC codes: A10A, A10B), anti-inflammatory and anti-rheumatic agents and non-steroids (ATC code: M01A), macrolides (ATC code: J01FA) and proton pump inhibitors (ATC code: A02BC) 6 months before the data index.

\section{Compliance with therapy among OAC users}

Persistence to therapy in terms of the percentage of patients still on treatment with the index drug during the last 3 months of observation was also assessed. Patients were excluded if they had a procedure of electrical cardioversion (ICD-9-CM procedure code: 99.6). An interruption of treatment was defined as the absence of prescriptions in the last 3 months of the observation period. This method is validated and has been used in previous studies. ${ }^{21,22}$

\section{Statistical analysis}

Standard descriptive statistical methods were used to analyze the patient's demographics and clinical status, to evaluate the proportion of treated patients in each drug category and to calculate the cohort of patients still on treatment with the index drug. In cases where data were not issuable for data privacy - results referred to less than four patients, as potentially reconductable to single individuals "Codice in materia di protezione dei dati personali [Code for protection of personal data]"38 - they have been reported as NI (not issuable). Statistical analyses were performed using Stata software version (StataCorp LP, College Station, TX, USA).

\section{Results}

From 2009 to 2012, we identified 1,413 patients with a diagnosis of AF (2.09\% of 67,517 patients of the 44 GPs). The numbers of patients identified during the 4 years of data screening were 365 and 354 in 2009 and 2010, respectively, and 346 and 348 in 2011 and 2012, respectively; of these patients, $49.9 \%$ were males. The frequency of AF increased with age, with a significant majority of cases observed in the elderly population. A total of 934 patients $(66.1 \%)$ had at least one cardiologic visit in the year prior to the index. During the 6 months before the index date, $33.2 \%$ patients had at least one prescription for $\beta$-blockers, while $27.3 \%$ and $20 \%$ patients had at least one prescription for proton pump inhibitors and statins, respectively. The baseline characteristics of the patients, stratified according to the treatment assignment, are described in Table 1.

At the time of the analysis, 559 patients $(39.56 \%$ of all patients with $\mathrm{AF})$ were treated with OACs, 424 patients $(30 \%$ of all patients with AF) received AP agents and 200 patients (14\% of all patients with AF) were without any prescription for ATs. Prescriptions for both an OAC and AP agent were given to $16.28 \%$ of patients; of these patients, only $4.17 \%$ were given an OAC plus an AP agent at the same time. The distribution of the study population stratified by treatment strategy assignment 1 year after the index date is shown in Table 2.

In the entire study population, the most frequent $\mathrm{CHA}_{2} \mathrm{DS}_{2}$-VASc scores were 4, 3 and 5+, occurring in $31.6 \%$, $26.1 \%$ and $18 \%$ of patients, respectively (Table 3 ). The distribution of ATs use according to stroke risk categories is 
Table I Clinical and demographic characteristics stratified by treatment strategy assignment

\begin{tabular}{|c|c|c|c|c|c|}
\hline & OAC, n (\%) & AP, n (\%) & Both prescriptions, n (\%) & None, n (\%) & Total, n (\%) \\
\hline Year of diagnosis & $559(100.0)$ & $424(100.0)$ & $230(100.0)$ & $200(100.0)$ & $1,4 \mid 3(100.0)$ \\
\hline 2009 & $145(39.7)$ & $119(32.6)$ & $58(15.9)$ & $43(11.8)$ & $365(100.0)$ \\
\hline 2010 & $146(4 \mid .2)$ & $98(27.7)$ & $61(17.2)$ & $49(13.8)$ & $354(100.0)$ \\
\hline 2011 & $130(37.6)$ & $119(34.4)$ & $54(15.6)$ & $43(12.4)$ & $346(100.0)$ \\
\hline 2012 & 138 (39.7) & $88(25.3)$ & $57(16.4)$ & 65 (18.7) & $348(100.0)$ \\
\hline Males* & $262(48.2)$ & $200(48.1)$ & $132(58.7)$ & $95(48.5)$ & $689(49.9)$ \\
\hline \multicolumn{6}{|l|}{ Age groups (years) } \\
\hline$<30$ & - & $\mathrm{NI}$ & - & $4(2.0)$ & $5(0.4)$ \\
\hline $30-64$ & $47(8.4)$ & $63(14.9)$ & $30(13.0)$ & $52(26.0)$ & $192(13.6)$ \\
\hline $65-74$ & $106(19.0)$ & $90(2 I .2)$ & $58(25.2)$ & $35(17.5)$ & $289(20.5)$ \\
\hline $75-84$ & $273(48.8)$ & $|3|(30.9)$ & $101(43.9)$ & $59(29.5)$ & $564(39.9)$ \\
\hline$\geq 85$ & $133(23.8)$ & $139(32.8)$ & $4 \mid(17.8)$ & $50(25.0)$ & $363(25.7)$ \\
\hline \multicolumn{6}{|l|}{ Previous diseases } \\
\hline Stroke & $109(19.5)$ & $70(16.5)$ & $60(26.1)$ & $24(12.0)$ & $263(18.6)$ \\
\hline Transient ischemic attack & $31(5.5)$ & $14(3.3)$ & $14(6.1)$ & $7(3.5)$ & $66(4.7)$ \\
\hline Hemorrhagic stroke & $\mathrm{NI}$ & $\mathrm{NI}$ & - & $\mathrm{NI}$ & $5(0.4)$ \\
\hline Bleeding/hemorrhage & $6 \mathrm{I}(10.9)$ & $34(8.0)$ & $23(10.0)$ & $18(9.0)$ & $136(9.6)$ \\
\hline Valve disease & $75(13,4)$ & $29(6.8)$ & I8 (7.8) & $18(9.0)$ & $140(9.9)$ \\
\hline Heart failure & $92(16.5)$ & $43(10.1)$ & $19(8.3)$ & $18(9.0)$ & $172(12.2)$ \\
\hline Hypertension & $516(92.3)$ & $375(88,4)$ & $210(91.3)$ & | 43 (7|.5) & $1,244(88.0)$ \\
\hline Diabetes & $90(16.1)$ & $66(15.6)$ & $46(20.0)$ & $24(12.0)$ & $226(16.0)$ \\
\hline Peripheral vascular disease & $72(12.9)$ & $61(14.4)$ & $49(21.3)$ & $15(7.5)$ & $197(13.9)$ \\
\hline Bone fractures & $51(9.1)$ & $43(10.1)$ & $24(10.4)$ & $15(7.5)$ & $133(9.4)$ \\
\hline Peptic ulcer & $34(6.1)$ & $33(7.8)$ & $13(5.7)$ & $13(6.5)$ & $93(6.6)$ \\
\hline Coagulation defects & $15(2.7)$ & $8(1.9)$ & $5(2.2)$ & $\mathrm{NI}$ & $31(2.2)$ \\
\hline Chronic bronchitis & $48(8.6)$ & $30(7.1)$ & $18(7.8)$ & $8(4.0)$ & $104(7.4)$ \\
\hline Obstructive chronic bronchitis & $27(4.8)$ & II (2.6) & $14(6.1)$ & $\mathrm{NI}$ & $55(3.9)$ \\
\hline Asthma & $20(3.6)$ & $16(3.8)$ & $10(4.3)$ & $8(4.0)$ & $54(3.8)$ \\
\hline Gastroesophageal reflux & $58(10.4)$ & $50(11.8)$ & $27(11.7)$ & $25(12.5)$ & $160(11.3)$ \\
\hline Disorders of thyroid gland & III (19.9) & $86(20.3)$ & $42(18.3)$ & $38(19.0)$ & $277(19.6)$ \\
\hline Dementia & II $(2.0)$ & II (2.6) & - & $5(2.5)$ & $27(1.9)$ \\
\hline Other cerebral degenerations & $4(0.7)$ & $\mathrm{NI}$ & - & - & $5(0.4)$ \\
\hline Sleep apnea & $14(2.5)$ & $9(2.1)$ & $5(2.2)$ & $\mathrm{NI}$ & $29(2.1)$ \\
\hline Myocardial infarction & $43(7.7)$ & $48(11.3)$ & $35(15.2)$ & $6(3)$ & $132(9.3)$ \\
\hline \multicolumn{6}{|l|}{ Drug use 6 months before index date } \\
\hline b-blocker agents & $211(37.7)$ & $130(30.7)$ & $90(39.1)$ & $38(19.0)$ & $469(33.2)$ \\
\hline Statins & $107(19.1)$ & $88(20.8)$ & $75(32.6)$ & $13(6.5)$ & $283(20.0)$ \\
\hline Organic nitrates & $26(4.7)$ & $32(7.5)$ & $14(6.1)$ & $\mathrm{NI}$ & $75(5.3)$ \\
\hline Antidiabetic drugs & $61(10.9)$ & $48(11.3)$ & $37(16.1)$ & $10(5.0)$ & $156(11.0)$ \\
\hline FANS & $35(6.3)$ & $25(5.9)$ & $16(7.0)$ & $6(3.0)$ & $82(5.8)$ \\
\hline Macrolides & $\mathrm{NI}$ & $\mathrm{NI}$ & $5(2.2)$ & - & $9(0.6)$ \\
\hline Proton pump inhibitors & $148(26.5)$ & $115(27.1)$ & $75(32.6)$ & $48(24.0)$ & $386(27.3)$ \\
\hline Antiarrhythmics & $47(8.4)$ & $35(8.3)$ & $21(9.1)$ & $12(6.0)$ & $115(8.1)$ \\
\hline \multicolumn{6}{|c|}{ Other healthcare resource used prior to the } \\
\hline \multicolumn{6}{|c|}{ index date } \\
\hline Cardiologic visits & $407(72.8)$ & $246(58.0)$ & I 74 (75.7) & $107(53.5)$ & $934(66.1)$ \\
\hline ECGs with Holter & $212(37.9)$ & $136(32.1)$ & $87(37.8)$ & 7I (35.5) & $506(35.8)$ \\
\hline ECGs & $213(38.1)$ & $97(22.9)$ & $76(33.0)$ & $5 I(25.5)$ & $437(30.9)$ \\
\hline Prosthetic heart valves & II (2.0) & - & $\mathrm{NI}$ & $\mathrm{NI}$ & $17(1.2)$ \\
\hline
\end{tabular}

Note: *Value was calculated only for patients for whom gender data were available $(n=I, 38 I)$.

Abbreviations: OAC, oral anticoagulant; AP, antiplatelet; b-blocker, beta blocker; ANS, anti-inflammatory and antirheumatic agents and non-steroids; ECG, echocardiogram; $\mathrm{NI}$, not issuable.

reported in Figure 1. We evaluated the HAS-BLED score; the results showed that a low proportion of patients had a high and a low HAS-BLED score, with the majority of patients having a moderate bleeding risk score (Table 3). The given combinations between the treatment options for each patient and the HAS-BLED scores are summarized in Figure 2. Data regarding INR tests were available in $64.6 \%$ of all patients treated with OACs. Among the OAC users, the percentage of patients still on treatment with the index drug during the last 3 months of observation was $76.9 \%$. 
Table 2 Distribution of the study population stratified by treatment strategy assignment I year after the index date

\begin{tabular}{|c|c|c|c|c|c|c|}
\hline \multirow[b]{2}{*}{ Treatment strategy assignment } & \multicolumn{2}{|l|}{3 months } & \multicolumn{2}{|l|}{6 months } & \multicolumn{2}{|l|}{ I year } \\
\hline & Patients $(n=1,4 \mid 3)$ & $\%$ & Patients $(n=1,413)$ & $\%$ & Patients $(n=1,413)$ & $\%$ \\
\hline OAC & 554 & 39.2 & 576 & 40.8 & 559 & 39.6 \\
\hline AP & 408 & 28.9 & 425 & 30.1 & 424 & 30.0 \\
\hline Prescriptions of both an OAC agent and an AP agent & 123 & 8.7 & 171 & 12.1 & 230 & 16.3 \\
\hline None & 328 & 23.2 & 241 & I7.I & 200 & 14.2 \\
\hline
\end{tabular}

Abbreviations: OAC, oral anticoagulant; AP, antiplatelet.

Table 3 Distribution of stroke risk and bleeding risk of patients according to the $\mathrm{CHA}_{2} \mathrm{DS}_{2}-\mathrm{VASc}$ and HAS-BLED scores, respectively

\begin{tabular}{lll}
\hline Score/risk category & $\begin{array}{l}\text { Distribution of patients" according to } \text { CHA }_{2} \text { DS }_{2} \mathbf{2}^{-} \\
\text {VASc score, } \mathbf{n}(\%)\end{array}$ & $\begin{array}{l}\text { Distribution of patients" according to HAS-BLED } \\
\text { score, } \mathbf{n}(\%)\end{array}$ \\
\hline 0 & $36(2.6)$ & $98(7.1)$ \\
1 & $89(6.4)$ & $409(29.6)$ \\
2 & $204(14.8)$ & $617(44.7)$ \\
3 & $358(25.9)$ & $204(14.8)$ \\
4 & $44 I(31.9)$ & $41(3.0)$ \\
$5+$ & $253(18.3)$ & $12(0.9)$ \\
\hline
\end{tabular}

Note: "HAS-BLED and $\mathrm{CHA}_{2} \mathrm{DS}_{2}-\mathrm{VASc}$ scores were calculated only for patients for whom gender data were available $(\mathrm{n}=\mathrm{I}, 38 \mathrm{I})$.

Abbreviations: HAS-BLED, hypertension, abnormal renal and liver function, stroke, bleeding, labile INR, elderly (age $>65$ years), drugs (other AP agents or NSAIDs) or alcohol history; INR, international normalized ratio; AP, antiplatelet; NSAID, nonsteroidal anti-inflammatory drug.

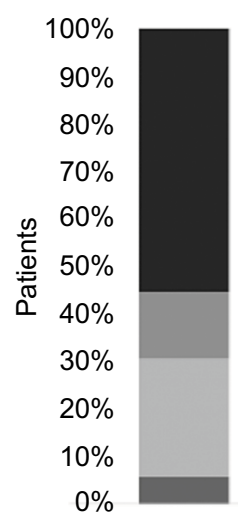

0

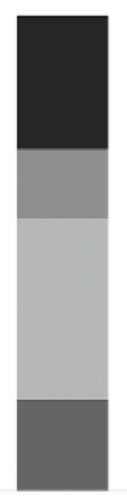

1

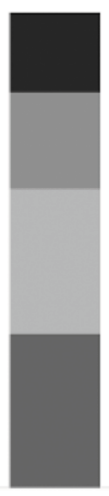

2

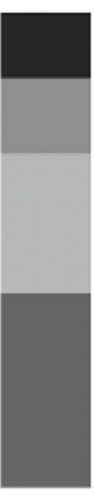

3

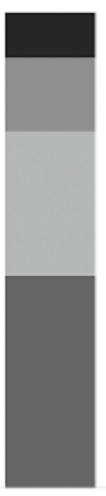

4

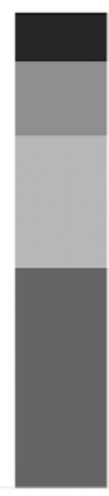

$5+$

$\mathrm{CHA}_{2} \mathrm{DS}_{2}$-VASc Score

$\square \mathrm{OAC}=\mathrm{AP} \square$ Both prescriptions $\square$ None

Figure I Stratification of treatment strategy assignment per risk category according to $\mathrm{CHA}_{2} \mathrm{DS}_{2}-\mathrm{VASc}$ score. Note: The $\mathrm{CHA}_{2} \mathrm{DS}_{2}-\mathrm{VASc}$ score was calculated only for patients where gender data were available $(\mathrm{n}=1,38 \mathrm{I})$.

Abbreviations: $\mathrm{OAC}$, oral anticoagulant; AP, antiplatelet.

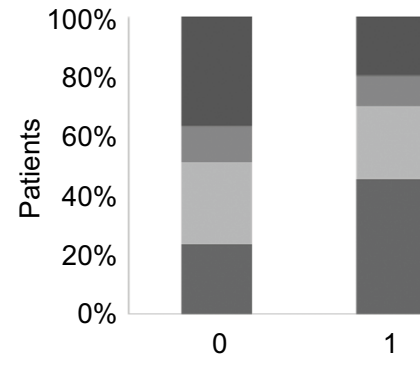

OACs only

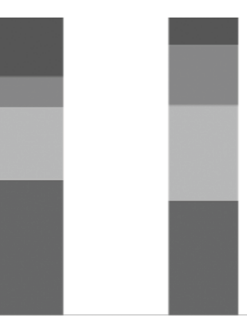

2

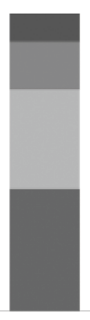

3

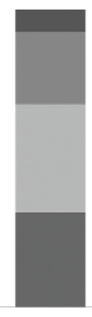

4

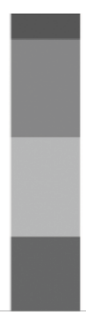

$5+$

HAS-BLED score

Figure 2 Stratification of treatment strategy assignment per bleeding risk category according to the HAS-BLED score.

Note: The HAS-BLED score was calculated only for patients where gender data were available $(n=1,38 I)$.

Abbreviations: HAS-BLED, hypertension, abnormal renal and liver function, stroke, bleeding, labile INR, elderly (age $>65$ years), drugs (other AP agents or NSAIDs) or alcohol history; OAC, oral anticoagulant; AP, antiplatelet; INR, international normalized ratio; NSAID, nonsteroidal anti-inflammatory drug. 


\section{Discussion}

AF is the most common sustained arrhythmia in Italy. ${ }^{17,18}$ We studied, retrospectively, a population of 1,413 patients with AF cared by 44 GPs. The AF prevalence varies considerably between countries, although this variance might partially be a function of the differences in the methods of data collection and the demographic characteristics of the populations investigated..$^{23,24}$ In previous studies, the prevalence and incidence were higher in men than woman, ${ }^{23}$ whereas in our study, the opposite trend was observed. In our study, the prevalence of AF was $2.09 \%$; this value is in accordance with what was reported previously in a retrospective Italian study (on patients being cared for by 233 GPs, homogeneously distributed across Italy), in which the prevalence of AF was estimated to be of $1.85 \% .^{18}$

The profile of comorbidities at baseline was in agreement with previous analyses and showed that hypertension was the most prevalent condition associated with AF patients. ${ }^{18,25}$

Our study shows that a considerable proportion of AF patients did not receive any prescription of ATs. Moreover, our finding shows that $55.8 \%$ of all patients enrolled were treated with OACs $(39.56 \%$ were prescribed an OAC and $16.2 \%$ had both prescriptions during the observation period); the OAC use rate was lower than expected compared with the Euro Heart Survey (where, among 2,706 patients enrolled, $\sim 64 \%$ patients received OAC due to AF $)^{26}$ or European countries. ${ }^{27,28}$ Our underutilization of OAC is in accordance with data observed in other two Italian studies. The survey conducted by Mazzaglia et $\mathrm{al}^{18}$ from 2001 to 2004 showed that in patients with AF, the use of OACs and AP agents was $26.6 \%$ and $30.7 \%$, respectively, and $5.5 \%$ of patients had both prescriptions. In the recent study, ISAF, ${ }^{17}$ in which a diagnosis of AF was confirmed in $2.04 \%$ of all the patients screened, only $46 \%$ of the entire population received OACs, 37.5\% were taking AP agents and 16.5\% had no AT treatment at all. Taken together, these data indicate that despite the growth in the awareness of the benefits of anticoagulation as a treatment for AF, the underuse of OAC remains evident. In 2007, the ARNO Cardiovascular Observatory documented a percentage of OACs prescription of $42.7 \%$ in patients with a primary diagnosis of AF and $37.7 \%$ in patients with a secondary diagnosis of AF from hospital discharge records in the first month of follow-up post-discharge. ${ }^{29}$

In the present study, we calculated the levels of stroke and bleeding risks according to risk stratification schemes. Although, HAS-BLED score is now recommended in European guideline ${ }^{1,30}$ to estimate major bleeding risk in anticoagulated AF patients, physicians rarely take into consideration HAS-BLED in prescribing the therapy. This could be explained by the fact that many risk factors for stroke are also risk factors for bleeding. A substantial percentage of patients were associated with moderate and high scores; based on this risk profile, although AT therapy is highly recommended in AF patients with a $\mathrm{CHA}_{2} \mathrm{DS}_{2}-$ VASc score of $>2$, we report underuse of AT therapies. OACs appear to be underused, even in patients with a high risk of stroke who might benefit from such medication. A recent review reported underuse of OAC in high-risk patients. ${ }^{13}$ In addition, the AntiThrombotic Agents in Atrial Fibrillation (ATA-AF) study, performed in 2012, showed that a considerable underuse of OAC was observed in eligible high-risk patients, in whom the prescription rate was only $56 \% .^{25}$

It is unclear why AF patients are untreated and guidelines are not followed in clinical practice. A recent Italian study ${ }^{31}$ analyzed the levels of knowledge and information on AF in the Italian population and the level of AF risk awareness by GPs and AF patients. The results showed that only one-third of Italians know that AF is perceived as a severe disease. In addition, Gensini et $\mathrm{al}^{31}$ showed an underuse of the scores for thromboembolic and hemorrhagic risk stratification recommended by the current guidelines and a frequent use of AP agents rather than OAC therapy.

When the analysis was conducted, there were no data available about novel oral anticoagulants (NOACs); nevertheless, recently published studies show that adoption of NOACs might have a positive effect on the undertreatment of $\mathrm{AF}^{32-34}$

In the current study, among the patients treated with OACs, $>75 \%$ of all OACs users were still on treatment during the last months of the follow-up period. A number of studies have reported that noncompliance with anticoagulation therapy could have a significant clinical effect by increasing the thromboembolic and stroke risk, which could lead to prolonged hospital admissions and residential care and could play an important role in increasing the consumption of health care resources and in worsening morbidity and mortality. ${ }^{35,36}$ During OAC therapy, the frequent performing of coagulation tests reminds the patient of the importance of such treatment, and the rate of discontinuation could be indicated by abnormal INR results. In our analysis, a percentage of OAC patient records did not contain information on the INR, and we could not establish if INR tests were not performed or if the INR values were not reported in our database. Although the monitoring requirements of OACs are generally thought 
of as a negative factor discouraging OAC use, regular monitoring measures of patients' compliance and the interface with expert health care providers might improve compliance to treatment. ${ }^{37}$ The lack of information on the INR monitoring in the administrative database points toward the need for a greater effort in formation/communication with GPs.

Our analysis has several limitations inherent to any observational study. First, the analyses were performed using the databases of one LHU; although GPs in Bologna have a well-managed collaborative audit project that could lead to actual health care benefits for users and great improvement in health care quality, the findings of this study must be interpreted with caution, and further larger studies are required to confirm these results. A second limitation is the relatively small sample size of patients with a confirmed diagnosis of AF. A third limitation of this study is that the reasons for noncompliance with treatment in the patients are not retrievable from the dataset. For this reason, we cannot exclude that the occurrence of important contraindications or the use of concomitant treatment with potentially interacting medication might also explain the treatment discontinuation. In addition, no important clinical information was available to us. Finally, the OAC daily dose is extremely variable, because it is dependent on patient-related factors; therefore, the precision of the method used to calculate the percentage of patients still on treatment with the index drug during the observation period is likely to be limited.

\section{Conclusion}

Our study emphasizes that in an Italian real-world setting, the burden of AF in general population from a public health point of view underscores the need for improvement in utilization of appropriate ATs in patients with known AF.

The present findings suggest that a proportion of patients do not receive or discontinue therapy for AF management. Considering these findings, other studies are needed to identify the reason why AF treatment is not optimal and the relevance of the implementation of educational interventions aimed at improving the clinical management of patients with AF.

\section{Acknowledgments}

The GP group consisted of Emanuela Aldrovandi, Paolo Amorati, Luigi Bagnoli, Antonio Balduzzi, Giulio Bandi, Salvatore Bauleo, Antonino Cammarata, Roberto Cau, Lucia Cecchini, Enrico Delfini, Cecilia Deni, Giancarlo Furlò, Fabio Gentili, Angela Inì, Marco Maccaferri, Carla Marzo, Angelo Masi, Annunzio Matrà, Gaito PieroMazzetti,
Giampiero Mazzoni, Federico Montanari, Dante Monti, Mara Mori, Massimo Oggianu, Maria Palasciano, Marcello Paolo, Laura Pittigliani, Stefano Quadrelli, Stefano Rubini, Marcello Salera, Sandra Santi, Alberto Serio, Matteo Siena, Elisabetta Simoncini, Luigi Simoni, Pietro Speziali, Luigi Spinnato, Cesare Tosetti, Pietro Velonà, Andrea Verri, Domenico Zisa, Donato Zocchi and Giuseppe Zoccoli.

\section{Author contributions}

All authors contributed toward data analysis, drafting and critically revising the paper and agree to be accountable for all aspects of the work .

\section{Disclosure}

The authors have no conflicts of interest to disclose. The opinions expressed in this article do not necessarily reflect the views of the authors' institutions.

\section{References}

1. Camm AJ, Lip GY, De Caterina R, et al. 2012 focused update of the ESC Guidelines for the management of atrial fibrillation: an update of the 2010 ESC Guidelines for the management of atrial fibrillation. Developed with the special contribution of the European Heart Rhythm Association. Eur Heart J. 2012;33(21):2719719.

2. Chugh SS, Havmoeller R, Narayanan K, et al. Worldwide epidemiology of atrial fibrillation: a Global Burden of Disease 2010 Study. Circulation. 2014;129(8):837-847.

3. Go AS, Hylek EM, Phillips KA, et al. Prevalence of diagnosed atrial fibrillation in adults: national implications for rhythm management and stroke prevention: the AnTicoagulation and risk factors in Atrial Fibrillation (ATRIA) Study. JAMA. 2001;285(18):2370-2375.

4. Feinberg WM, Blackshear JL, Laupacis A, Kronmal R, Hart RG. Prevalence, age distribution, and gender of patients with atrial fibrillation. Analysis and implications. Arch Intern Med. 1995;155(5):469-473.

5. Camm AJ, Kirchhof P, Lip GY, et al. Guidelines for the management of atrial fibrillation: the Task Force for the Management of Atrial Fibrillation of the European Society of Cardiology (ESC). Europace. 2010;12(10): $1360-1420$.

6. Prisco D, Cenci C, Silvestri E, Emmi G, Barnini T, Tamburini C. The risk stratification in atrial fibrillation. Intern Emerg Med. 2012;7(suppl 3):S233-S240.

7. Raviele A, Disertori M, Alboni P, et al [webpage on the Internet] Linee guida AIAC per la gestione e il trattamento della fibrillazione atriale. Aggiornamento 2013. G Ital Cardiol; 2013. Available from: http://www.giornaledicardiologia.it/articoli.php?archivio=yes\&vol_ id=1234\&id=13660. Accessed April 27, 2017.

8. Fuster V, Ryden LE, Cannom DS, et al. 2011 ACCF/AHA/HRS focused updates incorporated into the ACC/AHA/ESC 2006 Guidelines for the management of patients with atrial fibrillation: a report of the American College of Cardiology Foundation/American Heart Association Task Force on Practice Guidelines developed in partnership with the European Society of Cardiology and in collaboration with the European Heart Rhythm Association and the Heart Rhythm Society. J Am Coll Cardiol. 2011;57(11):e101-e198.

9. Curtis AB. Practice implications of the atrial fibrillation guidelines. $\mathrm{Am}$ J Cardiol. 2013;111(11):1660-1670.

10. Wasmer K, Eckardt L. Management of atrial fibrillation around the world: a comparison of current ACCF/AHA/HRS, CCS, and ESC guidelines. Europace. 2011;13(10):1368-1374. 
11. Anderson JL, Halperin JL, Albert NM, et al. Management of patients with atrial fibrillation (compilation of 2006 ACCF/AHA/ESC and 2011 ACCF/AHA/HRS recommendations): a report of the American College of Cardiology/American Heart Association Task Force on Practice Guidelines. J Am Coll Cardiol. 2013;61(18):1935-1944.

12. Hylek EM, Go AS, Chang Y, et al. Effect of intensity of oral anticoagulation on stroke severity and mortality in atrial fibrillation. $N$ Engl J Med. 2003;349(11):1019-1026.

13. Ogilvie IM, Newton N, Welner SA, Cowell W, Lip GY. Underuse of oral anticoagulants in atrial fibrillation: a systematic review. Am J Med. 2010;123(7):638.e4-645.e4.

14. Ferro D, Loffredo L, Polimeni L, Violi F. Underuse of oral anticoagulants in patients with nonvalvular atrial fibrillation in Italy. Intern Emerg Med. 2007;2(1):24-28.

15. Monte S, Macchia A, Pellegrini F, et al. Antithrombotic treatment is strongly underused despite reducing overall mortality among highrisk elderly patients hospitalized with atrial fibrillation. Eur Heart J. 2006;27(18):2217-2223.

16. Wilke T, Groth A, Pfannkuche M, et al. Real life anticoagulation treatment of patients with atrial fibrillation in Germany: extent and causes of anticoagulant under-use. J Thromb Thrombolysis. 2015;40(1):97-107.

17. Mazzaglia G, Filippi A, Alacqua M, et al. A national survey of the management of atrial fibrillation with antithrombotic drugs in Italian primary care. Thromb Haemost. 2010;103(5):968-975.

18. Zoni-Berisso M, Filippi A, Landolina M, et al. Frequency, patient characteristics, treatment strategies, and resource usage of atrial fibrillation (from the Italian Survey of Atrial Fibrillation Management [ISAF] study). Am J Cardiol. 2013;111(5):705-711.

19. Italian Medicine Agency (AIFA). Guideline for the Classification and Conduction of the Observational Studies on Medicines. 2017. Available from: https://www.agenziafarmaco.gov.it/ricclin/sites/default/files/ files_wysiwyg/files/CIRCULARS/Circular\%2031st\%20May\%202010. pdf. Accessed April 27, 2017.

20. Shah M, Avgil Tsadok M, Jackevicius CA, et al. Warfarin use and the risk for stroke and bleeding in patients with atrial fibrillation undergoing dialysis. Circulation. 2014;129(11):1196-1203.

21. Degli Esposti L, Sangiorgi D, Perrone V, et al. Adherence and resource use among patients treated with biologic drugs: findings from BEETLE study. Clinicoecon Outcomes Res. 2014;6:401-407.

22. Gerth WC. Compliance and persistence with newer antihypertensive agents. Curr Hypertens Rep. 2002;4(6):424-433.

23. Heeringa J, van derKuip DA, Hofman A, et al. Prevalence, incidence and lifetime risk of atrial fibrillation: the Rotterdam study. Eur Heart J. 2006;27(8): 949-953.

24. Levi M, Hobbs FD, Jacobson AK, et al. Improving antithrombotic management in patients with atrial fibrillation: current status and perspectives. Semin Thromb Hemost. 2009;35(6):527-542.

25. Di Pasquale G, Mathieu G, Maggioni AP, et al. Current presentation and management of 7148 patients with atrial fibrillation in cardiology and internal medicine hospital centers: the ATA AF study. Int J Cardiol. 2013; 167(6):2895-2903.

26. Nieuwlaat R, Capucci A, Lip GY, et al. Antithrombotic treatment in real-life atrial fibrillation patients: a report from the Euro Heart Survey on atrial fibrillation. Eur Heart J. 2006;27(24):3018-3026.
27. Murphy NF, Simpson CR, Jhund PS, et al. A national survey of the prevalence, incidence, primary care burden and treatment of atrial fibrillation in Scotland. Heart. 2007;93(5):606-612.

28. Friberg L, Hammar N, Ringh M, Pettersson H, Rosenqvist M. Stroke prophylaxis in atrial fibrillation: who gets it and who does not? Report from the Stockholm Cohort-study on Atrial Fibrillation (SCAF-study). Eur Heart J. 2006;27(16):1954-1964.

29. Osservatorio ARNO cardiovascolare [webpage on the Internet]. La prevenzione secondaria dopo un evento di sindrome coronarica acuta. 2017. Available from: http://www.cineca.it/it/pubblicazione/ osservatorio-arno-cardiovascolare-la-prevenzione-secondaria-dopoun-evento-di-sindrome. Accessed May 11, 2017.

30. Camm AJ, Pinto FJ, Hankey GJ, Andreotti F, Hobbs FDR; Writing Committee of the Action for Stroke Prevention Alliance. Non-vitamin $\mathrm{K}$ antagonist oral anticoagulants and atrial fibrillation guidelines in practice: barriers to and strategies for optimal implementation. Europace. 2015;17(7):1007-1017.

31.Gensini GF, Di Pasquale G, Vaccaro CM, et al. Indagine Censis sulla conoscenza in Italia della fibrillazione atriale a livello dei cittadini, dei medici di medicina generale e dei pazienti. [A Censis survey on atrial fibrillation awareness in the general population and among general practitioners and affected patients in Italy]. G Ital Cardiol Rome. 2014;15(1):37-43. Italian.

32. Kirley K, Rao G, Bauer V, Masi C. The role of NOACs in atrial fibrillation management: a qualitative study. J Atrial Fibrillation. 2016; 9(1):1416

33. De Caterina R, Renda G, Sangiuolo R, et al; Steering Committee del Registro Europeo PREFER in AF (vedi Appendice 1). La gestione del rischio tromboembolico nei pazienti con fibrillazione atriale in Italia: dati al basale del Registro Europeo PREFER in AF. [Management of thromboembolic risk in patients with atrial fibrillation in Italy: baseline data from the PREFER in AF European Registry]. G Ital Cardiol Rome. 2014;15(2):99-109. Italian.

34. Forslund T, Wettermark B, Hjemdahl P. Comparison of treatment persistence with different oral anticoagulants in patients with atrial fibrillation. Eur J Clin Pharmacol. 2016;72(3):329-338.

35. Brown TM, Siu K, Walker D, Pladevall-Vila M, Sander S, Mordin M. Development of a conceptual model of adherence to oral anticoagulants to reduce risk of stroke in patients with atrial fibrillation. J Manag Care Pharm. 2012;18(5):351-362.

36. Chen SY, Wu N, Gulseth M, et al. One-year adherence to warfarin treatment for venous thromboembolism in high-risk patients and its association with long-term risk of recurrent events. J Manag Care Pharm. 2013;19(4):291-301.

37. Hess PL, Mirro MJ, Diener HC, et al. Addressing barriers to optimal oral anticoagulation use and persistence among patients with atrial fibrillation: Proceedings, Washington, DC, December 3-4, 2012. Am Heart J. 2014;168(3):239.e1-247.e1.

38. Gruppo Di Lavoro Artiocolo 29 per la protezione dei dati. Parere 05/2014 sulle tecniche di anonimizzazione, adottato il 10 aprile 2014 [Working Group Article 29 for protection of data. Opinion 05/2014 on the anonymization techniques, Adopted on 10 April 2014]. Available from http://ec.europa.eu/justice/data-protection/article-29/documentation/opinion-recommendation/files/2014/wp216_it.pdf. Accessed June 14, 2017. Italian.
Vascular Health and Risk Management

\section{Publish your work in this journal}

Vascular Health and Risk Management is an international, peerreviewed journal of therapeutics and risk management, focusing on concise rapid reporting of clinical studies on the processes involved in the maintenance of vascular health; the monitoring, prevention and treatment of vascular disease and its sequelae; and the involvement of

\section{Dovepress}

metabolic disorders, particularly diabetes. This journal is indexed on PubMed Central and MedLine. The manuscript management system is completely online and includes a very quick and fair peer-review system, which is all easy to use. Visit http://www.dovepress.com/ testimonials.php to read real quotes from published authors. 